\title{
Making Sense of Mathematics Achievement in East Asia: Does Culture Really Matter?
}

\author{
Frederick K.S. Leung
}

\begin{abstract}
East Asian students have persistently performed well in recent international comparative studies of mathematics achievement, and I have been offering explanations from the perspective of the influence of the Confucian Heritage Culture (CHC), which is shared by these high performing East Asian countries. In this paper, two challenges to this cultural explanation will be dealt with: whether these East Asian countries really form a group and whether there is a more direct way to study the influence of culture on mathematics achievement. Three studies on secondary analyses of the TIMSS and PISA datasets are presented to support the assertion that the East Asian countries do form a cultural cluster, and preliminary results of a study that looks into the influence of the English and Chinese languages on students' assessment in mathematics are reported.
\end{abstract}

Keywords Culture - Confucian heritage culture (CHC) - East Asian countries • Language and mathematics learning - International studies of mathematics achievement

\section{Introduction: The Superior Mathematics Achievement of East Asian Students in International Studies}

In the citation for my Hans Freudenthal Medal 2013 by ICMI, my research was recognized as being "in comparative studies of mathematics education and on the influence of culture on mathematics teaching and learning" and one of my

Hans Freudenthal award.

F.K.S. Leung $(\bowtie)$

Faculty of Education, The University of Hong Kong, Pokfulam Road, Hong Kong

e-mail: frederickleung@hku.hk

(C) The Author(s) 2017

G. Kaiser (ed.), Proceedings of the 13th International Congress on Mathematical

Education, ICME-13 Monographs, DOI 10.1007/978-3-319-62597-3_13 


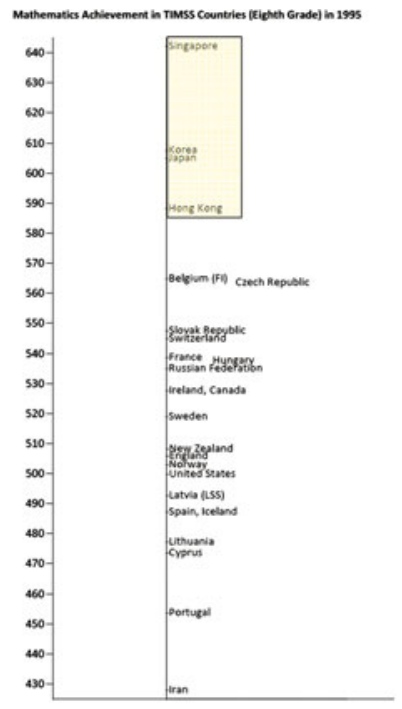

Mathematics Achievement in TIMSS Countries (Eighth Grade) in 1999
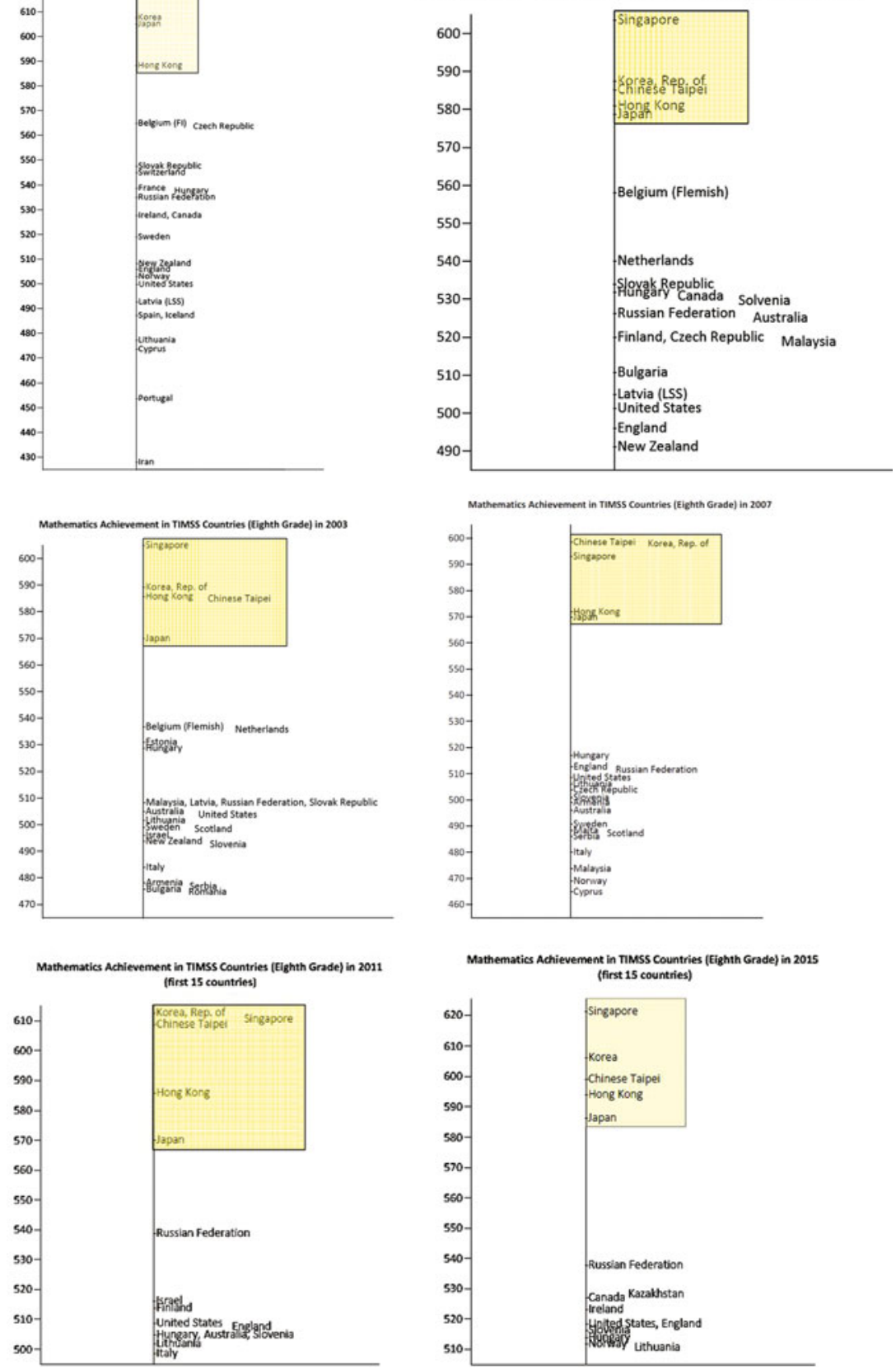

Fig. 1 Performance of East Asian countries in TIMSS 

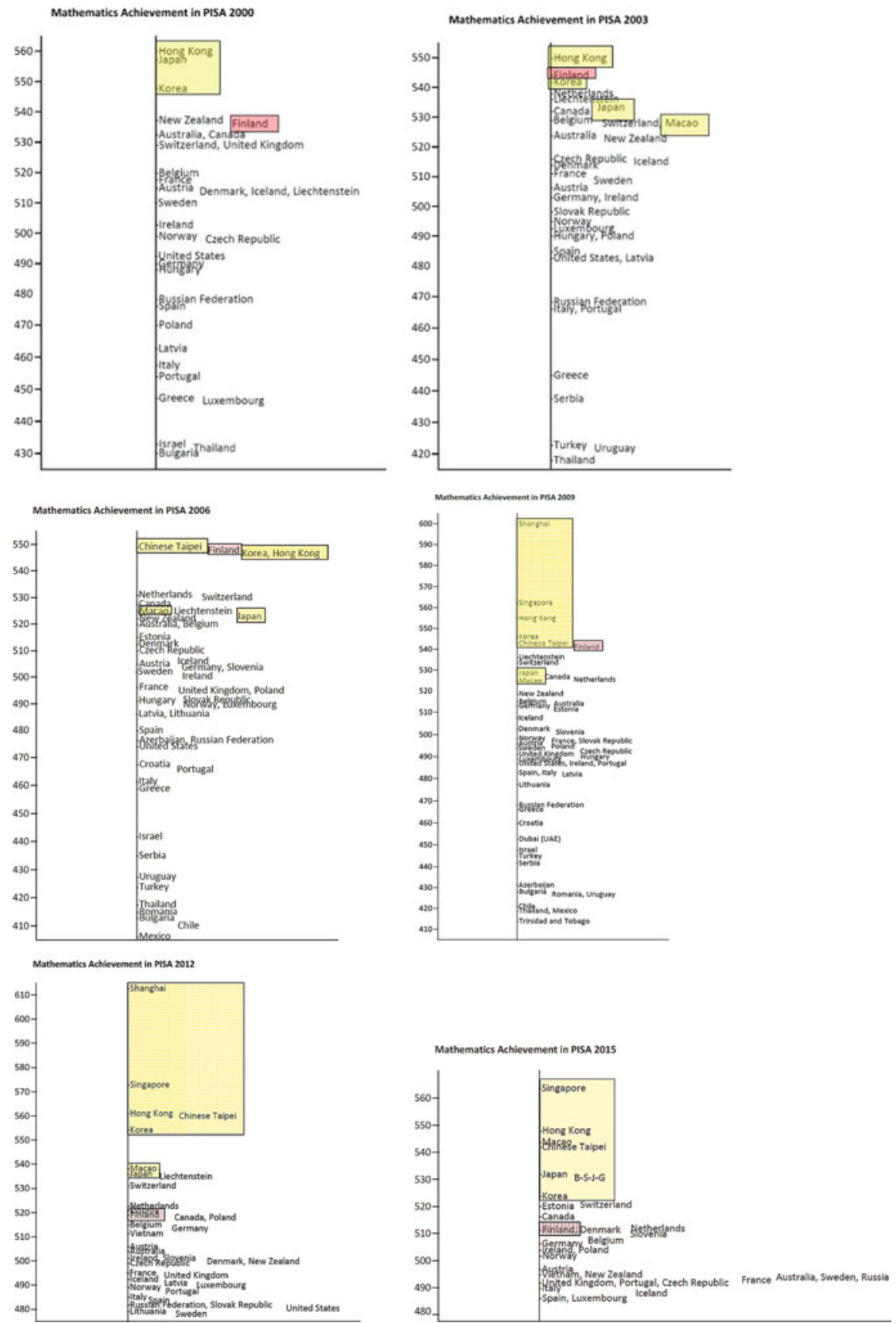

Fig. 2 Performance of East Asian countries in PISA 
contributions was "the utilization of the perspective of the Confucian Heritage Culture to explain the superior mathematics achievement of East Asian ${ }^{1}$ students in international studies" (ICMI, 2013) such as TIMSS and PISA. As can be seen from Figs. 1 and 2, East Asian countries consistently took up the top positions in the rankings in TIMSS and PISA (Beaton, Mullis, Martin, Gonzalez, Kelly, \& Smith, 1996; Mullis et al., 1997, 2000; Mullis, Martin, Gonzalez, \& Chrostowski, 2004; Mullis, Martin, \& Foy, 2008; Mullis, Martin, Foy, \& Arora, 2012; Mullis, Martin, Foy, \& Hooper, 2016; OECD, 2001, 2003, 2004, 2007, 2010, 2014, 2016), and this is what I meant by "superior performance" in my previous publications.

\section{A Cultural Explanation of the Superior Mathematics Achievement of East Asian Students}

In seeking an explanation for the superior mathematics achievement of East Asian students, I argued that these high-performing East Asian countries shared a common culture, referred to as "Confucian Heritage Culture" (CHC) by Ho (1991; quoted in Biggs, 1996, p. 46). I then examined the common values shared by these CHC countries that are related to education (Leung, 2001).

In putting forth the cultural thesis above, I encountered at least two queries or challenges:

(1) Do these East Asian countries really form a group distinct from other countries? Other than the fact that they rank high in international studies, are there other empirical data that show that they fall into a common group? (For example, Finland has also been performing very well in the recent cycles of PISA. But Finland does not share the East Asian culture.)

(2) Is there a more direct way to study whether culture does affect mathematics achievement (other than simply examining the common values shared by the $\mathrm{CHC}$ countries that are related to education)?

\section{Do These East Asian Countries Form a Cluster?}

In this section, I present results of three studies based on secondary analyses of the TIMSS and PISA data to show that there is evidence other than ranking in international studies that indicates that the East Asian countries do form a distinct cluster.

\footnotetext{
${ }^{1}$ In this paper, East Asian “countries" refer to the systems of Hong Kong, Japan, Korea, Singapore and Taiwan.
} 


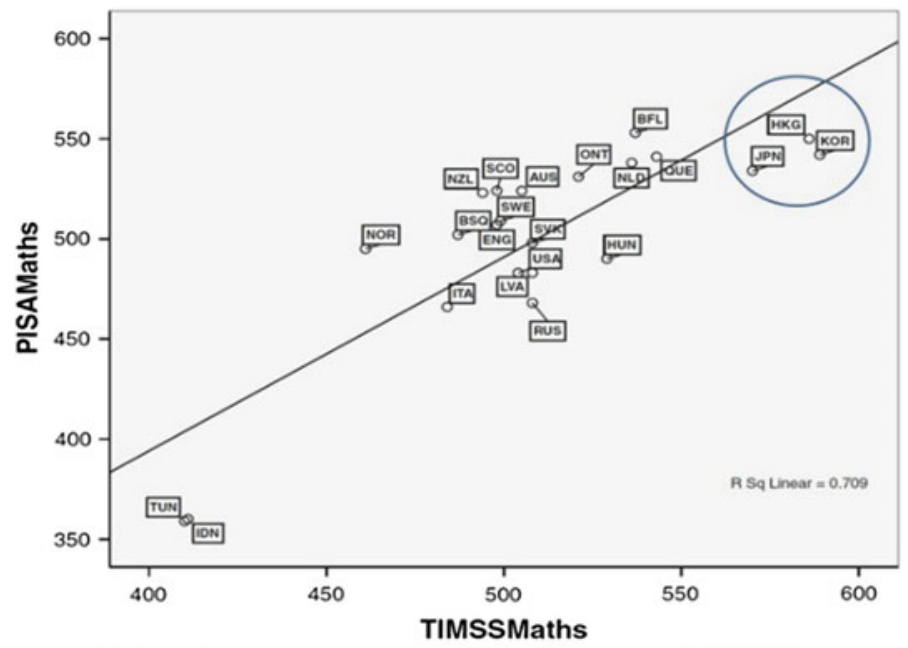

Mathematics country mean scores: PISA 2003 versus TIMSS 2003

Fig. 3 Prediction of PISA results from TIMSS results 2003

The first study by Wu (2009) covers a comparison of PISA and TIMSS 2003 achievement results in mathematics.

Twenty-two countries participated in both TIMSS and PISA $2003,{ }^{2}$ and $\mathrm{Wu}$ (2009) compared the performance of these 22 countries between TIMSS and PISA. Wu concluded that "content balance" and "years of schooling" explain the different achievements of countries in TIMSS and PISA 2003. In one of the analyses, Wu predicted these 22 countries' PISA results from their TIMSS results statistically, and the results are shown in Fig. 3.

As can be seen from Fig. 3, Hong Kong, Japan and Korea (the only East Asian countries that participated in the two studies) not only clustered near each other, but also all performed worse in PISA than expected from their TIMSS scores. What common characteristics do these East Asian countries share that cause them not only to perform well in both TIMSS and PISA but also to exhibit the same achievement pattern of performing worse in PISA than in TIMSS?

The second study by Lie (2014) seeks to identify similarities and differences between various groups of countries, referring to their relative weaknesses and strengths.

\footnotetext{
${ }^{2}$ TIMSS was conducted once every four years, and PISA was conducted once every three years. TIMSS tested students' achievement in mathematics and science, while PISA tested mathematics, science and reading literacy. Each cycle of PISA focuses on one of the three areas of study. It so happened that both TIMSS and PISA took place in 2003, and the area of focus for PISA 2003 was mathematics.
} 
In a presentation made at the 55th General Assembly meeting of IEA in Wien in October 2014, Lie examined the patterns of the item residuals ${ }^{3}$ of the TIMSS 2003 data to study the relative strengths and weaknesses of countries in their mathematics achievements. Lie used correlations and cluster analysis to examine the item residuals patterns, considering the international difficulty of the items and the overall scores of the items for the country. Lie identified patterns showing that there are groups of countries exhibiting similar strengths and weaknesses.

Eight clusters of countries are identified from this analysis, and I assign (arbitrary) labels to describe these clusters of countries as follows:

English-speaking: England, Scotland, New Zealand, Australia, Canada, USA, Ireland

North Europe: $\quad$ Netherlands, Norway, Sweden, Iceland, Denmark

Central Europe: Germany, Switzerland, Austria

South Europe: $\quad$ Portugal, Spain, Greece

Other: Iran, Thailand, Philippines, South Africa, Columbia, Kuwait

Western Europe: Belgium Fl, Belgium Fr, France

East Asia: $\quad$ Hong Kong, Singapore, Japan, Korea

East Europe: Czech Republic, Slovakia, Hungary, Lithuania, Russia, Latvia, Cyprus, Romania, Bulgaria, Israel.

Of interest to us is that once again the East Asian countries of Hong Kong, Singapore, Japan and Korea cluster together. That is, they do not only perform well in TIMSS 2003, they also share the same patterns of strengths and weaknesses in the performance.

The third study (Guo, 2014) examines the relation between time for studying mathematics and achievement.

In this paper, Guo (2014) examined the relationship between out-of-school study time and mathematics achievement based on the PISA 2012 data. In Guo's analysis, mathematics achievement was plotted against out-of-school study time for each of the PISA 2012 countries. Guo found that a quadratic relation between achievement and study time is a better fit of the data than a linear relation is, and he computed and plotted the quadratic relation for each country. Each of these quadratic graphs then represents a relation between mathematics achievement and the out-of-school study time that is characteristic for that country. Guo then ran a cluster analysis for these characteristic relations and obtained four different clusters of countries (see Fig. 4). Interestingly, Hong Kong, Japan, Korea, Shanghai (China), Singapore and Taiwan again fall into the same cluster, showing that the kind of relationship between mathematics achievement and out-of-school study time is in some way similar among these East Asian countries and cities.

\footnotetext{
3"Item residual" is defined as how much better or worse than expected a national $p$-value is.
} 


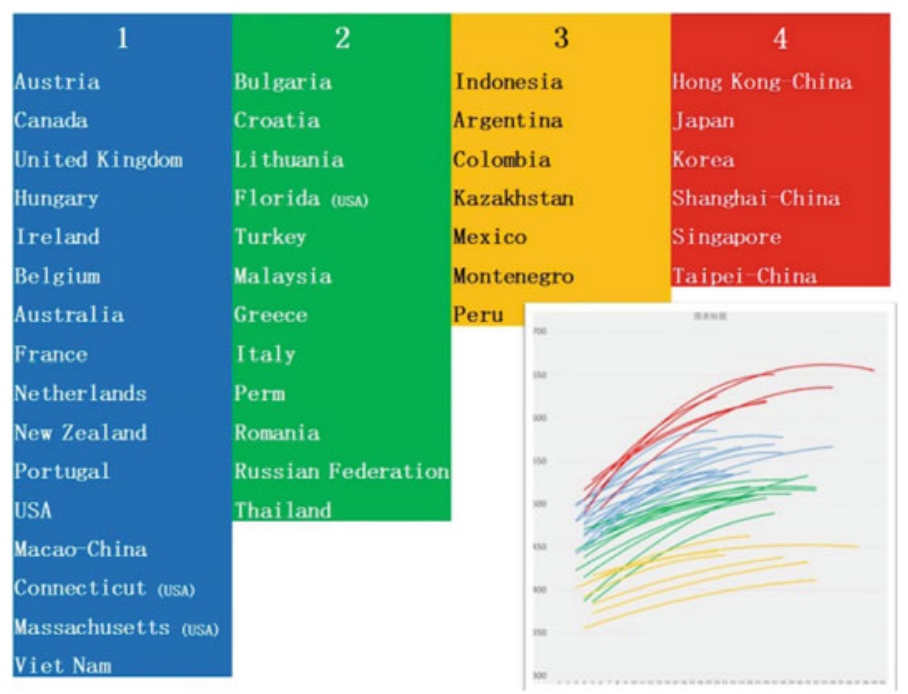

Fig. 4 Clusters of countries by relationship between mathematics achievement and out-of-school study time (Source PowerPoint slide from Guo (2014), reproduced with permission)

\section{Discussion}

From the three studies discussed, we can conclude that there is further evidence that these East Asian countries do fall into a cluster. These countries or cities are all in East Asia, but there is of course no reason for us to believe that the geographic location in itself will cause these countries to perform in a similar manner. So back to my original question: Could these countries form a cultural cluster?

At a plenary panel during ICME-12 on Mathematics Education in East Asia (see also Leung, 2006), I examined the cultural commonalities of these East Asian countries, namely $\mathrm{CHC}$, and I discussed the following characteristics of $\mathrm{CHC}$, which are deemed to be related to mathematics learning:

(1) Examination culture

(2) Belief in effort

(3) Memorization and practice

(4) Reflection.

To answer the question of whether these East Asian countries really form a cluster, the discussions in this section show that there is further evidence other than the ranking of these countries in international studies that shows that these East Asian countries do form a cluster. Since there is much cultural commonality among these East Asian countries, it is probable that these countries form a cultural cluster. 


\section{Does Culture Really Affect Mathematics Achievement?}

The argument in the last section is at best an inference; that is, from the various analyses of the achievement data in TIMSS and PISA, we can conclude that the East Asian countries do form a cluster, and, on the other hand, these countries also share a common culture. So maybe it is their common culture that has led their students to achieve and to behave in a similar manner. However, is there a more direct way of studying whether culture really affects mathematics achievement?

\section{What Is Culture?}

To study the relationship between culture and mathematics achievement, we first need to examine what culture is. In the literature, there are different descriptions and definitions of culture. One definition offered by Smith et al. is that culture is "the fabric of ideas, ideals, beliefs, skills, tools, aesthetic objects, methods of thinking, customs and institutions" (Smith, Stanley, \& Shores, 1957, p. 4). Examining these elements of culture defined by Smith et al., I can classify them as belonging to either superstructure or base structure (using a Marxist notion):

Superstructure: ideals, beliefs, ideas, methods of thinking

Base structure: skills, tools, customs, institutions, aesthetic objects.

\section{The Crucial Role of Language}

I would further argue that, mediating these two levels of structure, language plays a critical role; i.e., elements at the basic structure shape or determine the elements at the superstructure through the medium of language, since beliefs, ideas, etc., are constructed through the medium of language (see Fig. 5). This is in accordance with a social constructivist view of mathematics learning:

Social constructivism views mathematics as a social construction ... Human language, rules and agreement play a key role in establishing and justifying the truths of mathematics ... The basis of mathematical knowledge is linguistic knowledge, conventions and rules, and language is a social construction. (Ernest, 1991, p. 42)

\section{Ideological lúcals, beliefs, (values), ideas, methods of thinking Physical Skiths, tools, customs, institutions, aesthetic objects, (artefacts)}

Fig. 5 Elements of culture at the basic structure and superstructure levels mediated by language 
All experiences (including the experience of mathematics learning) are mediated by language (Gadamer, 1979), thought and language develop together and conception evolution depends on language experience (Vygotsky, 1986).

We do not know why languages that are so different have evolved from different cultures (the tower of Babel?). We know some basic human experiences are common across cultures; some are shaped by the environment and some are developed within particular historical contexts. These give rise to commonalities and differences in different languages (perhaps many more differences than commonalities). In any case, it is clear that language is the medium and tool for mathematics learning, but this important component of culture has hardly been studied in the past. One possible reason for this lack of attention to the role of language may be the assumption held by many that mathematics is a "universal language" and that it is learned in roughly the same way through different languages.

\section{Language Competence and Mathematics Achievement}

In the literature, Aiken (1972) showed that reading vocabulary, reading comprehension, mechanics of language and spelling have higher correlations with arithmetic reasoning than with arithmetic fundamentals at all elementary grade levels. To solve word problems or problem-solving types of questions, the language factor has a more important role than when solving the bare number problems (problems without context). However, do different languages make a difference to mathematics learning? How do we study the relationship between language and mathematics learning and achievement?

There are two approaches to studying the relationship between language and mathematics learning and achievement. The first I would call a theoretical or hypothetical approach. In this approach, we study the question of whether the language structures (e.g., the language used in textbooks and in test items) of different languages differ in complexity and hence have the potential to have an impact on students' processing of mathematics and test items. The second approach is an empirical one, where we study the question of whether students in different language groups process mathematics (in their brains) differently: Does the same mathematics content or test item exert the same or different cognitive demands on the students?

In the theoretical approach, we analyse the linguistic structures of mathematics texts or test items in different languages and compare their complexity. In the empirical approach, we compare the "behaviours"4 of students from different language groups when they are processing the same mathematics contents. In studying

\footnotetext{
${ }^{4}$ By behaviours, we mean whether the brain functions in the same way or in different ways when we process the same mathematics in different languages.
} 
these "internal" behaviours, the functions of the brain are either inferred indirectly from external behaviours (e.g., paper and pencil tests, think-aloud method, clinical observation) or directly observed using neuroscientific equipment.

\section{The Theoretical/Hypothetical Approach}

\section{English and the East Asian languages}

In the literature, scholars have discussed the features of the East Asian languages ${ }^{5}$ (Chinese, Japanese and Korean). East Asian languages are very different from Western languages such as English, and some have argued that there are features of the Chinese language that are favourable to the learning of mathematics. Fuson and Kwon (1991) argued that the irregular systems of number words in the English language affect students' numerical learning. The English language system of number words does not directly name the values of ten and one in two digit numbers as in some East Asian languages such as Korean and Chinese. Some features of English make it even more difficult to see the underlying tens and ones structures and how the first nine numbers are reused to make the decade words.

Leung and Park (2009) explored the interplay between the names of geometric figures in English, Chinese and Korean and students' capability in identifying the geometric figures. Names of some geometric figures in the three languages were analysed, and a test on identifying and defining these geometric figures was administered to Grade 8 students from the three language groups in Hong Kong, Seoul and San Diego. Students were then interviewed on the answers to the test. It was found that the way geometric figures are named and defined in different languages might have had an impact on students' identification of the geometric figures as well as their understanding of the properties of the figures.

Galligan (2001) outlined the differences between the Chinese and English written languages in terms of syntax, orthography, phonology and semantics. She argued that all four linguistic features influence the processing of mathematical text. Galligan's study found some evidence for a Chinese language advantage with respect to number sense and possibly to fractions, logical connectives and relational word problems as well.

At ICME-12, Leung, Park, Shimizu, and Xu (2012) discussed features of the Chinese language, that the Chinese language is logographic (rather than alphabetical and phonetic as in English). Leung et al. observed that the use of "classifiers" in the Chinese language "unscramble the confusion that otherwise surrounds

\footnotetext{
${ }^{5}$ The Japanese and Korean languages are strongly influenced by the Chinese language. Chinese characters (Hanja) were used as the written form of the Korean language before the 15th century, and Kanji (Chinese characters) are still widely used in the Japanese language today.
} 
conservation of numbers" (Brimer \& Griffin, 1985, p. 23) and mentioned the advantage of the regular number system in Chinese for learning mathematics. As far as spoken Chinese is concerned, Leung et al. pointed out the monosyllabic nature of the Chinese language, and that the short pronunciation of the numbers zero to ten makes it easy to process mathematics.

As for written Chinese, Leung et al. discussed the logographic nature of the Chinese characters. The orthography of Chinese writing is based on the spatial organization of the components (radicals) of the Chinese characters. Chinese characters possess visual properties such as connectivity, closure, linearity and symmetry, which are faster and easier to be captured by vision (Lai, 2008).

Leung et al. also discussed the different language use in Chinese and English: Ideas are organised differently in the two languages. Using the address of his office as an example, when writing the address in English, one starts with the smallest unit (the room, namely Room 312), then progressively extends it to the building (Runme Shaw Building), the institution (Faculty of Education, the University of Hong Kong), the road where the institution is (Pokfulam Road), the city (Hong Kong) and then finally the largest unit, the country (China). In contrast, in Chinese, one starts with the largest unit, the country (China [中國]), then the city (Hong Kong [香港]), the street (Pokfulam Road [薄扶林道]), the institution (Faculty of Education, the University of Hong Kong [香港大學教育學院]), the building (Runme Shaw Building [邵仁枚樓]), and finally the room (Room 312 [312室]).

How will this different language use affect students' understanding of mathematics? Will a Chinese speaker and an English speaker conceptualize geometric figures differently? For example, when confronted with a complicated geometric figure, will an English student start with the smallest units and view them in the context of the larger units, whereas a Chinese student may start with the larger picture and zoom into the smaller units? These are issues that remain to be studied.

\section{The Empirical Approach}

\section{Clinical Studies}

Miura, Kim, Chang, and Okamoto (1988) compared the cognitive representations of American, Chinese, Japanese and Korean first graders to determine if there might be variations in those representations resulting from numerical language characteristics that differentiate Asian and non-Asian language groups. Children were asked to construct various numbers using base-10 blocks. Miura et al. found that "Chinese, Japanese and Korean children preferred to use a construction of tens and ones to show numbers-place value appeared to be an integral component of their representations" (Miura et al., 1988, p. 1445), whereas English-speaking children preferred to use a collection of units, suggesting that they represent number as a grouping of counted objects. More Asian children than American children were 
found to be able to construct each number in two different ways, which suggests greater flexibility of mental number manipulation.

In a study by Lai and Leung (2012) on the visual perceptual abilities of Chinese-speaking and English-speaking children, the Developmental Test of Visual Perception (DTVP) was administered to 41 native Chinese-speaking children (with a mean age of 5 years and 4 months) in Hong Kong and 35 native English-speaking children (with a mean age of 5 years and 2 months) in Melbourne. The results show that Chinese-speaking children significantly outperformed the English-speaking children on general visual perceptual abilities. More interestingly, Chinese-speaking students' performance on visual-motor integration tasks was found to be far better than that of their counterparts, while the two groups of students performed similarly on motor-reduced visual perceptual tasks. Leung and Lai suggested that the written language format of Chinese might have contributed to the enhanced performance of Chinese-speaking children in the visual-motor integration tasks.

\section{Neuroscience Studies}

Tang et al. (2006) used fMRI to demonstrate a differential cortical representation of numbers between native Chinese and English speakers. Native English speakers were found to largely employ a language process that relies on the left perisylvian cortices for mental calculation such as a simple addition task. In contrast, native Chinese speakers tended to engage a visuo-premotor association network for the same task. In both groups, the inferior parietal cortex was activated by a task for numerical quantity comparison, but fMRI connectivity analyses revealed a functional distinction between Chinese and English groups among the brain networks involved in the task. These results indicate that the different biological encoding of numbers may be shaped by the visual reading experience during language acquisition and other cultural factors such as mathematics learning strategies and education systems, which cannot be explained completely by the differences in languages per se.

\section{The Influence of the Chinese and English Languages on Students' Processing of Mathematics}

Leung reported on an ongoing research project entitled "The influence of the Chinese and English languages on students' processing of mathematics word problems". The project investigates the differences in linguistic structure between the TIMSS mathematics word-problem items in Chinese and in English and the impact of the differences on Chinese- and English-speaking fourth graders in 
Taiwan and Australia, respectively, when they process the mathematics items in the two languages.

There is an assumption in international studies of mathematics achievement such as TIMSS and PISA that although these studies test students in different languages, the tests are testing the same mathematics achievement. That is, once the accuracy of the translation of test items is ensured, the mathematics knowledge and the cognitive demands on students measured by items in different languages are equivalent. All ranking of countries in international studies is based on this assumption, but is this assumption valid?

\section{The Research Questions of the Research Project are:}

1. What are the differences in linguistic structure between some TIMSS 2011 mathematics word-problem items in Chinese and in English?

2. What are the behavioural differences between Chinese- and English-speaking fourth graders when they process mathematics items in the two languages in terms of their eye movements while working on word problems?

3. How are the linguistic structures of mathematics items in Chinese and in English affecting students' processing of the items?

\section{Design of the Study}

There are three stages in the design of the study:

1. Examine the syntactic structures of the TIMSS items

(a) Item difficulties (performance differences) by different sub-domains under the domain of number

(b) Quantizing the syntactic structures of the two languages (Chinese and English)

(c) Linking and comparing the results of $a$ and $b$.

2. Analyse the linguistic differences

3. Verify 1 and 2 above by eye-tracking studies in Taipei and Adelaide; Primary 4 students from the two different language groups will be selected to join the eye-tracking study. 


\section{Social Network Analysis}

Social network analysis is employed to study the complexity of the linguistic structures of test items in the two languages. Indices such as centrality, density and prestige score are calculated for analysis, and syntactic dependency network is utilized to determine the elements of the language network. A vertex represents a different linguistic unit such as words or characters, and the edges describe the relations between these units. The indices assess which words play more important roles in helping students to solve mathematics word problems. These indices of the language network are calculated using the social network analysis software UCINET.

All the 65 word problems in the number domain of the TIMSS 2011 Primary 4 test will be analysed. The kinds of linguistic networks (indices) that affect students' processing of the items will be identified. In addition, to explore whether the linguistic structures of the items will affect students' processing of the items, 16 out of the 65 items that students in the two places find easiest and most difficult (according to the average performance of the students in Australia and Taiwan) will be chosen for the eye-movement phase of the study. Figure 6 shows some preliminary results of the social network analysis for an item (in Chinese and in English).

\section{Eye-Tracking Study}

Eye tracker monitoring provides a precise record of on-line reading behaviours that are composed of fixations and saccades of the eyes. It is generally assumed that increased time spent on a particular area reflects increased cognitive processing of that information. Through examining records of the eye-tracking, one can assess the relative amount of time spent on a given area of text.

Fig. 6 Preliminary results of the social network analysis
Paint comes in 5 liter cans. Sean needs 37 liters of paint. How many cans must he buy?

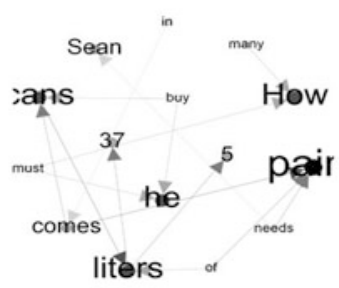

一罐油漆有5公升。 小杰需要 37 公升的油漆, 他须买多少罐油漆?

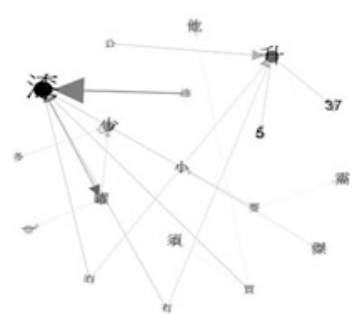


Since the Grade 4 TIMSS items will be analysed in this study, Grade 4 students will be sampled for the eye-tracking study. Purposive sampling of students of different genders and abilities (in terms of both language and mathematics achievement) from schools with different student abilities and social and economic status (SES) background in Taipei and Adelaide will be employed. Some preliminary results of the eye-tracking study record of a student in Taiwan and a student in Australia working on the same item (in Chinese and in English, respectively) are shown in Fig. 7.

\section{Data Analysis}

The data set in this study consists of (1) the results of the social-network analysis on the language complexity of the TIMSS mathematics word problems in Chinese and in English, and (2) records of the parts of the word problems in the two languages to which students pay more attention, as measured by the length of time the students
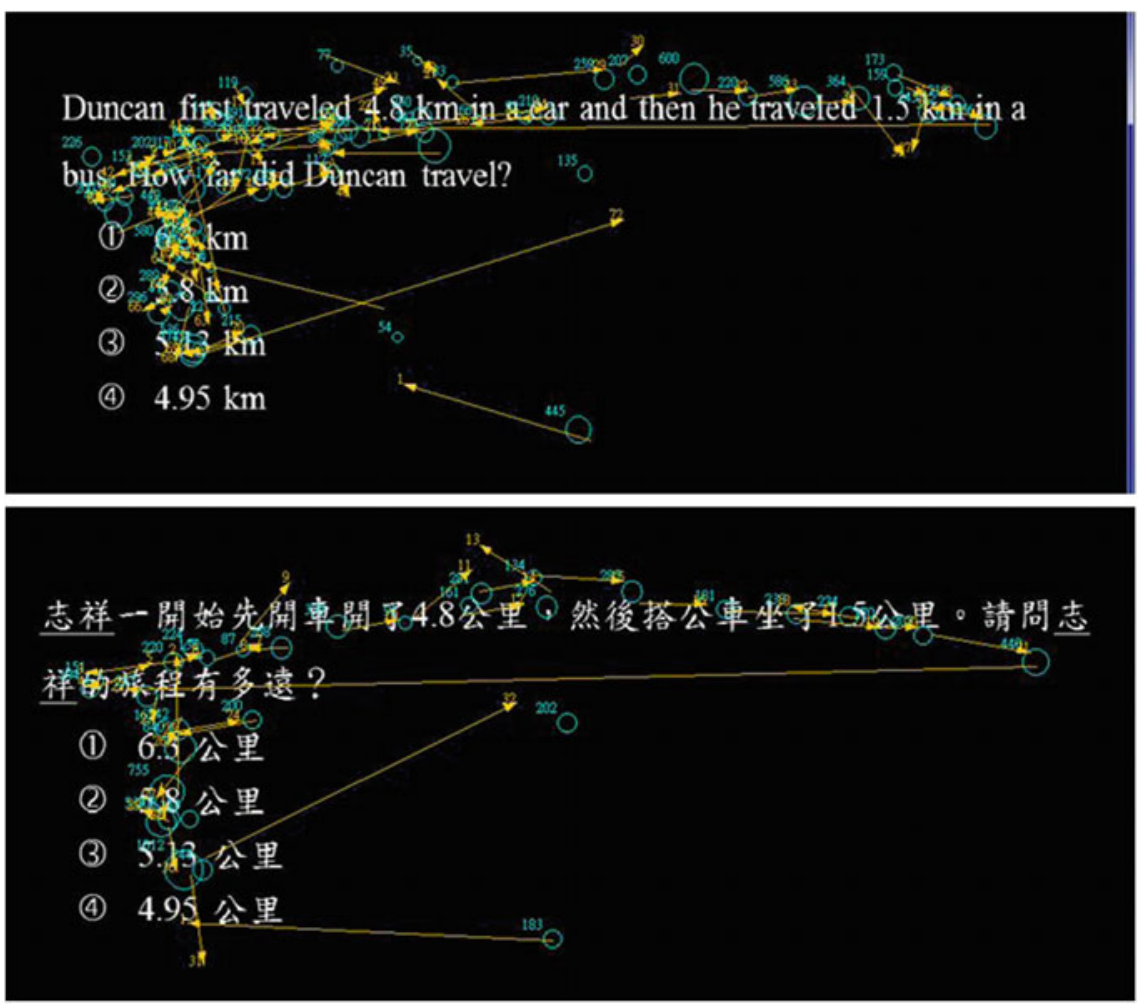

Fig. 7 Preliminary results of the eye-tracking study 
fix their eyes on those parts. The two categories of data will be analysed to investigate how the linguistic structures of the TIMSS mathematics items in Chinese and in English are affecting students' processing of the items.

\section{Significance of the Study and Further Research}

This study will fill a gap in the knowledge of how language has an impact on mathematics learning and achievement. It may even throw light on why East Asian students outperform their Western counterparts in mathematics achievement in international studies such as TIMSS.

The study may be extended to examining test items in other mathematics domains and including other languages (such as Korean). Other neuroscientific technology (such as near infrared spectroscopic imaging [NIRSI]) may be employed to study brain activity in an even more direct manner.

\section{Conclusion}

In this paper, we have argued that as far as mathematics education and achievement are concerned, the East Asian countries do form a cluster distinct from countries in other regions of the world. It has been argued that this cluster of countries shares a common culture, namely the Confucian Heritage Culture (CHC), and there seem to be elements in $\mathrm{CHC}$ that explain student achievement in mathematics. In particular, East Asian languages seem to influence mathematics learning and assessment in ways different from Western languages.

To answer the question posed in the title of this paper: "Does culture really matter?" the answer is still: "Probably". However, there is more evidence today that it is probable than there was 20 years ago!

\section{References}

Aiken, L. R. (1972). Language factors in learning mathematics. Review of Educational Research, 42, 359-385.

Beaton, A. E., Mullis, I. V. S., Martin, M. O., Gonzalez, E. J., Kelly, D. L., \& Smith, T. A. (1996). Mathematics achievement in the middle school years. Chestnut Hill, MA: International Study Center, Boston College.

Biggs, J. B. (1996). Western misconceptions of the confucian-heritage learning culture. In D. A. Watkins \& J. B. Biggs (Eds.), The Chinese learner (pp. 45-67). Hong Kong: Comparative Education Research Centre.

Brimer, A., \& Griffin, P. (1985). Mathematics achievement in Hong Kong secondary schools. Hong Kong: Centre of Asian Studies, The University of Hong Kong. 
Ernest, P. (1991). The philosophy of mathematics education. London: The Falmer Press.

Fuson, K., \& Kwon, Y. (1991). Chinese-based regular and European irregular systems of number words: The disadvantages for English-speaking children. In K. Durkin \& B. Shire (Eds.), Language in mathematical education (pp. 211-226). Milton Keynes, GB: Open University Press.

Gadamer, H. G. (1979). Philosophical hermeneutics. Berkeley: University of California Press.

Galligan, L. (2001). Possible effects of english chinese language differences on the processing of mathematical text: A review. Mathematics Education Research Journal, 13(2), 112-132.

Guo, K. (2014). Relation between time for studying mathematics and achievement. Paper presented at the First Chinese Mathematics Education Conference. Beijing, April.

Ho, D. Y. F. (1991). Cognitive socialization in confucian heritage cultures. Paper presented to Workshop on Continuities and Discontinuities in the Cognitive Socialization of Minority Children. Washington DC: US Department of Health and Human Services, June 29-July 2.

ICMI. (2013). Citation of 2013 Freundenthal Awardee. Retrieved January 23, 2017 from http:// www.mathunion.org/icmi/activities/awards/past-recipients/the-hans-freudenthal-medal-for2013

Lai, M. Y. (2008). In An exploratory study into Chinese and English children's visual perceptual and their spatial and geometric conceptions in Piagetian tasks (Unpublished doctoral dissertation). The University of Hong Kong.

Lai, M. Y., \& Leung, F. K. S. (2012). Visual perceptual abilities of Chinese-speaking and English-speaking children. Perceptual and Motor Skills, 114(2), 433-445.

Leung, F. K. S. (2001). In search of an East Asian identity in mathematics education. Educational Studies in Mathematics, 47, 35-52.

Leung, F. K. S. (2006). Mathematics education in East Asia and the West: Does culture matter? In F. K. S. Leung, K. D. Graf, \& F. J. Lopez-Real (Eds.) Mathematics education in different cultural traditions: A comparative study of East Asia and the West, The 13th ICMI Study (pp. 21-46). New York: Springer.

Leung, F. K. S., \& Park, K. M. (2009). The influence of language on the conception of geometric figures. Proceedings of PME, 33(1), 418.

Leung, F. K. S., Park, K. M., Shimizu, Y., \& Xu, B. (2012). Mathematics education in East Asia. Plenary panel, ICME-12, Seoul, 13 July.

Lie, S. (2014). Similarities and differences between groups of countries concerning relative weaknesses and strengths. http://www.iea.nl/fileadmin/user_upload/General_Assembly/55th_ GA/GA55_relative_weaknesses_and_strengths_groups.pdf. Accessed January 13, 2017.

Miura, I. T., Kim, C. C., Chang, C. M., \& Okamoto, Y. (1988). Effects of language characteristics on children's cognitive representation of numbers: Cross-national comparisons. Child Development, 59, 1445-1450.

Mullis, I. V. S., Martin, M. O., Beaton, A. E., Gonzalez, E. J., Kelly, D. L., \& Smith, T. A. (1997). Mathematics achievement in the primary school years. Chestnut Hill, MA: International Study Center, Boston College.

Mullis, I. V. S., Martin, M. O., \& Foy, P. (2008). TIMSS 2007 international mathematics report. Chestnut Hill, MA: TIMSS and PIRLS International Study Center, Boston College.

Mullis, I. V. S., Martin, M. O., Foy, P., \& Arora, A. (2012). TIMSS 2011 international results in mathematics. Chestnut Hill, MA: TIMSS and PIRLS International Study Center, Boston College.

Mullis, I. V. S., Martin, M. O., Foy, P., and Hooper, M. (2016). TIMSS 2015 international results in mathematics. TIMSS and PIRLS International Study Center, Boston College. http:// timssandpirls.bc.edu/timss2015/international-results/. Accessed January 13, 2017.

Mullis, I. V. S., Martin, M. O., Gonzalez, E. J., \& Chrostowski, S. J. (2004). TIMSS 2003 international mathematics report. Chestnut Hill, MA: TIMSS and PIRLS International Study Center, Boston College.

Mullis, I. V. S., Martin, M. O., Gonzalez, E. J., Gregory, K. D., Garden, R. A., O’Connor, K. M., et al. (2000). TIMSS 1999 international mathematics report. Chestnut Hill, MA: International Study Center, Boston College. 
Organisation for Economic Co-operation and Development. (2001). Knowledge and skills for life: First results from PISA 2000. Paris: OECD Publications.

Organisation for Economic Co-operation and Development. (2003). Literacy skills for the world of tomorrow-Further results from PISA 2000. Paris: OECD Publications.

Organisation for Economic Co-operation and Development. (2004). Learning for tomorrow's world -First results from PISA 2003. Paris: OECD Publications.

Organisation for Economic Co-operation and Development. (2007). In PISA 2006: Science competencies for tomorrow's World: Volume 1: Analysis. Paris: OECD Publications.

Organisation for Economic Co-operation and Development. (2010). PISA 2009 results: What students know and can do. Paris: OECD Publications.

Organisation for Economic Co-operation and Development. (2014). PISA 2012 results: What students know and can do (Volume I, Revised edition, February 2014): Student performance in mathematics, reading and science. Paris: OECD Publications.

Organisation for Economic Co-operation and Development. (2016). PISA 2015 Results (Volume I): Excellence and equity in education. Paris: OECD Publications.

Smith, B. O., Stanley, W. O., \& Shores, J. H. (1957). Fundamentals of curriculum development. New York: Harcourt, Brace and World Inc.

Tang, Y., Zhang, W., Chen, K., Feng, S., Ji, Y., Shen, J., et al. (2006). Arithmetic processing in the brain shaped by cultures. Proceedings of the National Academy of Science of the United States of America, 103(28), 10775-10780.

Vygotsky. (1986). Thought and Language. Cambridge: MIT Press.

Wu, M. (2009). A comparison of PISA and TIMSS 2003 achievement results in mathematics. Prospects, 39, 33-46.

Open Access Except where otherwise noted, this chapter is licensed under a Creative Commons Attribution 4.0 International License. To view a copy of this license, visit http://creativecommons. org/licenses/by/4.0/.

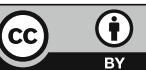

